\title{
Epac Mediates a cAMP-to-PKC Signaling in Inflammatory Pain: An Isolectin B4(+) Neuron-Specific Mechanism
}

\author{
Tim B. Hucho, Olayinka A. Dina, and Jon D. Levine \\ National Institutes of Health Pain Center, University of California, San Francisco, San Francisco, California 94143
}

The $\epsilon$ isoform of protein kinase $\mathrm{C}$ ( $\mathrm{PKC} \epsilon$ ) has emerged as a critical second messenger in sensitization toward mechanical stimulation in models of neuropathic (diabetes, alcoholism, and cancer therapy) as well as acute and chronic inflammatory pain. Signaling pathways leading to activation of $\mathrm{PKC} \epsilon$ remain unknown. Recent results indicate signaling from cAMP to PKC. A mechanism connecting cAMP and PKC, two ubiquitous, commonly considered separate pathways, remains elusive. We found that, in cultured DRG neurons, signaling from cAMP to PKC $\epsilon$ is not mediated by PKA but by the recently identified cAMP-activated guanine exchange factor Epac. Epac, in turn, was upstream of phospholipase C (PLC) and PLD, both of which were necessary for translocation and activation of PKC $\epsilon$. This signaling pathway was specific to isolectin B4-positive [IB4(+)] nociceptors. Also, in a behavioral model, cAMP produced mechanical hyperalgesia (tenderness) through Epac, PLC/PLD, and PKC $\epsilon$. By delineating this signaling pathway, we provide a mechanism for cAMP-to-PKC signaling, give proof of principle that the mitogen-activated protein kinase pathway-activating protein Epac also stimulates PKC, describe the first physiological function unique for the IB4 $(+)$ subpopulation of sensory neurons, and find proof of principle that G-protein-coupled receptors can activate PKC not only through the G-proteins $\alpha_{\mathrm{q}}$ and $\beta \gamma$ but also through $\alpha_{\mathrm{s}}$.

Key words: nociception; inflammation; intracellular signaling; $\beta$-adrenergic receptor; cAMP; PKC; Epac; PLD; IB4

\section{Introduction}

The cardinal symptom of inflammation is increased sensitivity to mechanical stimuli (mechanical hyperalgesia or tenderness). The understanding of the underlying intracellular signaling pathways, as well as the mechanoreceptors involved, remains fragmentary. Nevertheless, one signaling component, the $\epsilon$ isoform of protein kinase C (PKC $\epsilon$ ), has turned out to be important in nociceptor sensitization caused by inflammation (Khasar et al., 1999b; Numazaki et al., 2002; Sweitzer et al., 2004), peripheral neuropathies such as diabetes (Joseph and Levine, 2003a), chronic alcoholism (Dina et al., 2000), and cancer chemotherapy (Dina et al., 2001; Joseph and Levine, 2003b), as well as the transition from acute to chronic pain (Aley et al., 2000; Parada et al., 2003a,b). However, a signaling pathway leading to activation of PKC $\epsilon$ remains still to be elucidated.

Surprisingly, we recently found an indication for signaling from cAMP to PKC, suggesting that the signaling through adenylyl cyclase (AC)/cAMP does not involve PKA but branches upstream of PKA to activate PKC (Gold et al., 1998; Parada et al., 2005). However, a mechanism to account for signaling from cAMP to PKC, in nociception or other functional context, has yet to be established.

Recently, in a non-neuronal cell line, cAMP has been shown to

\footnotetext{
Received Jan. 20, 2005; revised May 8, 2005; accepted May 9, 2005.

This work was supported by the National Institutes of Health. We thank Drs. Hans Thönen, Louis Reichardt, Melitta Schachner, and Thomas Jentsch for helpful discussion of the data.

Correspondence should be addressed to Tim Hucho, National Institutes of Health Pain Center, University of California, San Francisco, 521 Parnassus Avenue, P.0. Box 0440, San Francisco, California 94143. E-mail: hucho@itsa.ucsf.edu.

DOI:10.1523/JNEUROSCI.0285-05.2005

Copyright $\odot 2005$ Society for Neuroscience $\quad$ 0270-6474/05/256119-08\$15.00/0
}

activate not only PKA but also the guanine exchange factor Epac (de Rooij et al., 1998; Kawasaki et al., 1998). Epac in turn activates a newly identified phospholipase, phospholipase C $\epsilon$ (PLC $\epsilon$ ) (Schmidt et al., 2001), and could therefore potentially activate novel PKCs, such as PKC $\epsilon$, through phospholipase-produced diacylglycerol (DAG) (Parekh et al., 2000). While the role of Epac in activation of mitogen-activated protein kinases (MAPKs) is a matter of intensive ongoing investigation (Enserink et al., 2002; Keiper et al., 2004), Epac is thus far not known to mediate activation of PKCs.

In the model of epinephrine-induced PKC $\epsilon$-mediated hyperalgesia (Khasar et al., 1999b; Parada et al., 2003b), we tested the hypothesis that cAMP is upstream of PKC $\epsilon$ and that Epac, through phospholipases, mediates the cAMP-PKC cross talk, leading to translocation and activation of PKC $\epsilon$ and to the establishment of inflammatory pain.

\section{Materials and Methods}

Antibodies. Antibodies and lectins used in this study were as follows: PKC $\epsilon$-specific monoclonal mouse antibody (BD Biosciences, Franklin Lakes, NJ), $\beta_{2}$-adrenergic receptor $\left(\beta_{2}\right.$-AR)-specific polyclonal rabbit antiserum, polyclonal rabbit anti-Epacl serum (Santa Cruz Biotechnology, Santa Cruz, CA), monoclonal mouse NeuN (neuronal nuclear antigen)-specific antibody (Chemicon, Temecula, CA), isolectin B4 (IB4)-Alexa Fluor 568 (Molecular Probes, Eugene, OR), donkey rabbitspecific FITC-conjugated, donkey mouse-specific rhodamineconjugated secondary antibody (Jackson ImmunoResearch, West Grove, $\mathrm{PA}$ ), and PKC $\epsilon$-specific rabbit serum [SN134; provided by Dr. Robert Messing, University of California, San Francisco (UCSF)].

Drugs. 1-Butanol, alprenolol, D-609, epinephrine, forskolin, (-)isoproterenol, and 1-[6-((17 $\beta$-3-methoxyestra-1,3,5(10)-trien-17yl)amino)hexyl]-2,5-pyrrolidine-dione (U73343) were purchased from 
Sigma (St. Louis, MO); 2-butanol was purchased from Fluka (Sigma); bisindolylmaleimide I (BIM), cholera toxin, $\epsilon \mathrm{V} 1-2$, 1-[6-((17 $\beta-3-$ methoxyestra-1,3,5(10)-trien-17-yl)amino)hexyl]-1 $H$-pyrrole-2,5dione (U73122), 4-cyano-3-methylisoquinoline (CMIQ), and 8-(4chlorophenylthio)-2'-O-methyl-cAMP (CPTOMe) were purchased from Calbiochem (La Jolla, CA); Nembutal was purchased from Abbott Laboratories (Irving, TX); (+)-1-[2,3-(dihydro-7-methyl-1 $\mathrm{H}$-inden-4yl)oxy]-3-[(1-methylethyl)amino]-2-butanol-hydrochloride (ICI 118,551) was purchased from Tocris Cookson (Ellisville, MO); the PKA catalytic subunit was purchased from New England BioLabs (Beverly, MA).

Chemicals. Chemicals used in this study were as follows: trypsin from Worthington Biochemical (Lakewood, NJ); collagenase from Roche Diagnostics (Indianapolis, IN); NeurobasalA (without phenol red) and B27 from Invitrogen (Carlsbad, CA); glutamine, MEM, HBSS, and penicillin/ streptavidin solution from UCSF Cell Culture Facility; bovine serum albumin (BSA), DMSO, glutamate, paraformaldehyde (PFA), and Triton X-100 from Sigma; normal goat serum and Vectashield from Vector Laboratories (Burlingame, CA).

Animals. Behavioral experiments were performed on male Sprague Dawley rats (200-300 g; Charles River Laboratories, Hollister, CA). Animals were housed in a controlled environment in the Animal Care Facility of the University of California, San Francisco, under a $12 \mathrm{~h}$ light/ dark cycle. Food and water were available ad libitum. Care and use of animals conformed to National Institutes of Health guidelines. The UCSF Committee on Animal Research approved the experimental protocols. All efforts were made to minimize the number of animals used.

Dorsal root ganglia cultures. Cultures of dissociated dorsal root ganglia (DRG) were prepared from male Sprague Dawley rats (200-300 g; Charles River Laboratories), adapting a protocol used by us previously (Khasar et al., 1999b). Rats were anesthetized with an overdose of Nembutal (50 mg/animal, s.c.). L1-L6 DRGs were removed, desheathed, pooled, and incubated with collagenase [final concentration (f.c.), $0.125 \% ; 1 \mathrm{~h} ; 37^{\circ} \mathrm{C}$, followed by a trypsin digest (f.c., $0.25 \% ; 7 \mathrm{~min}, 37^{\circ} \mathrm{C}$ ). Cells were separated by trituration with a fire-polished Pasteur pipette. Axon stumps and dead cells were removed by straining (40 $\mu \mathrm{m}$ mesh), followed by centrifugation ( $3 \mathrm{~min}, 500 \mathrm{~g}$ ). Cells were resuspended in 12 $\mathrm{ml}$ of NeurobasalA/B27 media and plated $0.5 \mathrm{ml} /$ culture $(0.5$ DRG equivalents) onto polyornithine/laminin-precoated glass coverslips $(12 \mathrm{~mm}$ diameter) and incubated overnight in 24 well plates at $37^{\circ} \mathrm{C}$ in $5 \% \mathrm{CO}_{2}$. Variability between batches of NeurobasalA media and its B27 supplement, resulting in varying translocation of PKC $\epsilon$ after stimulation, was counteracted by the addition of up to $1 \mu \mathrm{M}$ ethanol (according to the technical support of Invitrogen, $<2.5 \%$ of the ethanol concentration already in the medium).

Stimulation. After a $15-20 \mathrm{~h}$ incubation, to allow cells to adhere to coverslips, the cells were stimulated. To ensure homogeneous dispersion of the stimulants, $250 \mu \mathrm{l}$ of the $500 \mu \mathrm{l}$ medium was removed, mixed thoroughly with the respective activator/inhibitor, and added back to the same culture. Inhibitors were added at a concentration of $10 \times \mathrm{IC}_{50}$ values, $15 \mathrm{~min}$ before stimulation. Activators were added for the indicated time in concentrations based on literature reports. For all agonists, time courses were established (some data not shown). Negative controls (unstimulated cells) were treated alike but without the addition of any pharmaceutical reagent. Although we used the physiological stimulus epinephrine for the in vivo experiments, we used the $\beta$-AR agonist isoproterenol in vitro for identification of the $\beta$-AR subtype. After treatment, the cells were washed once with PBS and fixed with PFA [4\%, 10 min, room temperature (RT)].

Immunocytochemistry. PFA-fixed cells were permeabilized with $0.1 \%$ Triton X-100 (10 min, RT), followed by three washes with $0.1 \%$ BSA/PBS (5 min, RT). After blockage of unspecific binding sites (5\% BSA/10\% normal goat serum/PBS, $1 \mathrm{~h}, \mathrm{RT}$ ), the cultures were probed with the respective primary antibody in $1 \% \mathrm{BSA} / \mathrm{PBS}$ (overnight, $4^{\circ} \mathrm{C}$ ), washed three times (1\% BSA/PBS, $5 \mathrm{~min}, \mathrm{RT}$ ), and incubated with the secondary fluorophore-coupled antiserum (f.c., 1:200, 1 h, RT). After three final washes (PBS, 5 min, RT), the cultures were mounted with Vectashield onto microscope slides and sealed with nail polish.

Evaluation of PKC€ translocation. Cells were evaluated with a Nikon (Tokyo, Japan) Microphot FXA microscope, using a $50 \times$ oil-immersion objective. Fifty randomly selected cells per culture were evaluated. Data are plotted as mean percentage of translocating cells per evaluated culture \pm SEM based on the number of evaluated cultures. All counting was done in blind manner by the same observer. All treatments have been repeated with DRG neurons from different rats, on at least 2 separate days. Confocal images were taken with a $100 \times$ oil-immersion objective using a Zeiss (Oberkochen, Germany) Axiovert 100 microscope attached to an MRC 1000 confocal microscope (Bio-Rad, Hercules, CA). Epifluorescent images were taken with a $63 \times$ oil-immersion objective using a Zeiss Axiovert 100 microscope.

Testing of mechanical nociceptive threshold. The nociceptive flexion reflex was quantified using the Randall Selitto paw pressure device (Analgesymeter; Stoelting, Wood Dale, IL), which applies a linearly increasing mechanical force to the dorsum of the rat's hindpaw. The nociceptive mechanical threshold was defined as the force in grams at which the rat withdrew its paw. The protocols for this procedure have been described previously (Taiwo and Levine, 1989; Dina et al., 2003). Baseline pawwithdrawal threshold was defined as the mean of six readings before test agents were injected. Each paw was treated as an independent measure, and each experiment was performed on a separate group of rats. Each group of rats was treated with only one agonist and/or antagonist injected peripherally by the intradermal route. Measurement of nociceptive threshold was taken $30 \mathrm{~min}$ after the administration of the hyperalgesic mediator. All behavioral testing was done between 10:00 A.M. and 4:00 P.M.. The blocking agents were injected as described previously (Khasar et al., 1995, 1999a). Because it is less membrane permeable, injections of the PKC $\epsilon$ inhibitor ( $\epsilon \mathrm{V} 1-2)$ (Johnson et al., 1996) and the PKA catalytic subunit (Slice and Taylor, 1989) were always preceded by administration of $2.5 \mu \mathrm{l}$ of distilled water in the same syringe, separated by a small air bubble, to produce hypo-osmotic shock, thereby enhancing cell membrane permeability to the drug (Khasar et al., 1995, 1999a). The onset of mechanical hyperalgesia is already statistically significant after $2 \mathrm{~min}$ (Khasar et al., 1999a) mirroring the cellular results. The mechanical threshold was tested $30 \mathrm{~min}$ after injection of the respective stimulus, a time point of plateauing maximal response.

Statistical analysis. All statistical comparisons were made with one-way ANOVAs followed by Dunnet's multiple-comparison post hoc test, the $p$ values of which are given.

\section{Results \\ $\boldsymbol{\beta}_{2}$-Adrenergic receptor activation translocates PKC $\epsilon$ in DRG neurons}

To investigate the second-messenger signaling pathway upstream of PKC $\epsilon$, we evaluated translocation of PKC $\epsilon$ in dissociated dorsal root ganglion neurons, a central step in the activation of PKCs (Dorn and Mochly-Rosen, 2002) and an established surrogate measurement of PKC activation (Cesare et al., 1999). As observed by stimulation with bradykinin and phorbol ester (Cesare et al., 1999), also the $\beta$-AR agonist isoproterenol induced translocation of PKC $\epsilon$ to the plasma membrane of DRG neurons (Fig. 1A). Because of the intense cytoplasmic PKC $\epsilon$ signal, potential translocation to other intracellular targets was not evaluated.

A dose-response curve established that $1 \mu \mathrm{M}$ isoproterenol produced translocation in a maximal number of cells (cultures evaluated, $n=8 ; 21.3 \% \pm 2.8 \%$ PKC $\epsilon$-translocating cells) (Fig. $1 B)$. Translocation of PKC $\epsilon$ was transient, peaking at $\sim 30 \mathrm{~s}$, decaying by $90 \mathrm{~s}$, and returning to baseline after $5 \mathrm{~min}$ (Fig. 1C). Induction of translocation by isoproterenol was mediated by $\beta_{2}$-AR as it was inhibited by the $\beta_{2}$-AR-specific antagonist ICI 118,551 ( $n=8 ; 3.0 \% \pm 1.1 \%$ PKC $\epsilon$-translocating cells) (Fig. $1 C$ ). ICI 118,551 is described as an inverse agonist not only blocking receptor activation but also reducing its baseline activity (Bond et al., 1995), reflected by the decrease in baseline PKC $\epsilon$ translocation. 
A
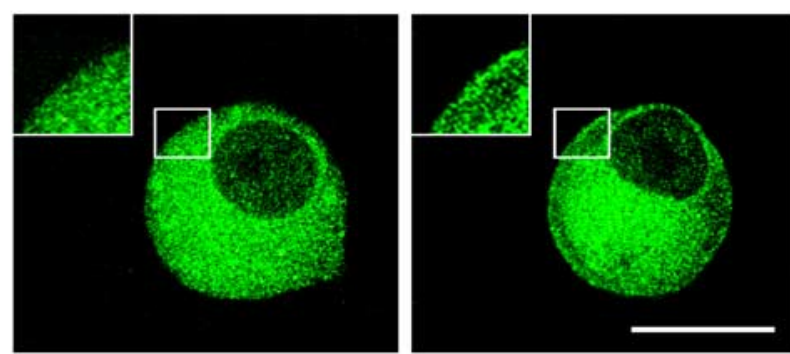

B

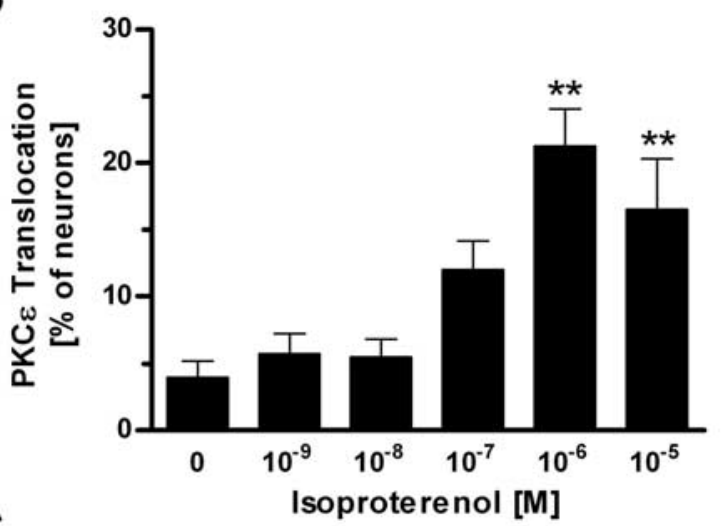

C

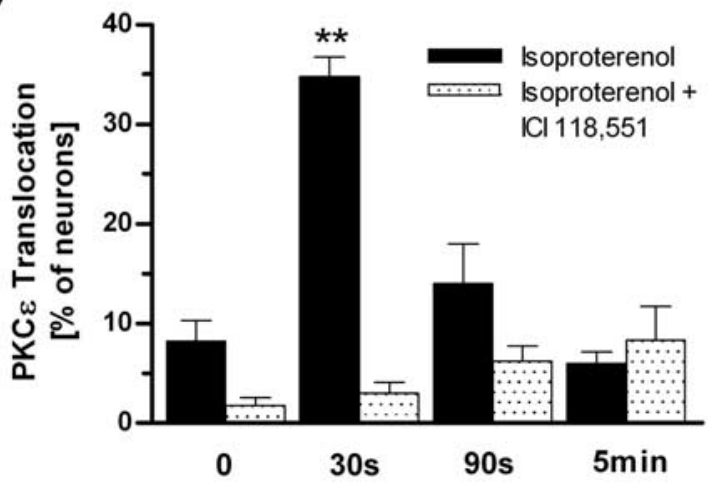

Time of Treatment

Figure 1. $\quad \beta_{2}$-AR agonist induced translocation of PKC $\epsilon$ in cultured DRG neurons. $\boldsymbol{A}$, Confocal images of representative untreated (left) versus isoproterenol-treated (1 $\mu \mathrm{M}, 30 \mathrm{~s}$; right) cultured DRG neurons. Cultures were fixed after treatment, incubated with the affinity-purified PKC $\epsilon$-specific antiserum SN134 (1:1000), and detected with FITC-coupled donkey anti-rabbit IgG serum (1:200). Insets, Enlarged area, indicated by the white frame. After isoproterenol treatment, a portion of PKC $\epsilon$ can be seen to translocate to the plasma membrane. Scale bar, 20 $\mu \mathrm{m}$. $\boldsymbol{B}$, Percentage of neurons demonstrating, after $30 \mathrm{~s}$, PKC $\epsilon$ translocation to the plasma membrane in response to indicated concentrations of isoproterenol. C, Percentage of neurons demonstrating PKC $\epsilon$ translocation with isoproterenol (1 $\mu \mathrm{m})$ stimulation, for indicated time points. Filled bars represent cultures treated with $1 \mu \mathrm{m}$ isoproterenol. Cultures represented by dotted bars were pretreated for 15 min with the $\beta_{2}$-AR-specific inhibitor ICI 118,551 (50 $\mu \mathrm{M}$ ) before stimulation with $1 \mu \mathrm{m}$ isoproterenol. ${ }^{* *} p<0.01$. Error bars represent SEM.

PKC $\epsilon$ translocation is mediated by $\alpha_{s}$ and AC but not by PKA To establish that the $\beta_{2}$-AR signals to PKC through cAMP, we applied the well described activator of $\alpha_{\mathrm{s}}$, cholera toxin, to the cell cultures, classically leading to a rise in intracellular cAMP. Translocation of PKC $\epsilon$ to the plasma membrane was observed, starting $30 \mathrm{~s}$ after treatment and peaking by $90 \mathrm{~s}(n=6 ; 15.2 \pm 3.0 \%$ and $24.0 \pm 1.9 \%$, respectively, of neurons showing PKC $\epsilon$ translocation) (Fig. $2 B$ ).

Because $\alpha_{\mathrm{s}}$ activates AC (Neves et al., 2002), we used the well established activator of AC, forskolin, to test for its involvement in the signaling cascade leading to PKC $\epsilon$ translocation. With a maximal response time of $30 \mathrm{~s}$, forskolin also induced the translocation of PKC $\epsilon$ to the plasma membrane $(n=6 ; 22.3 \pm 4.2 \%$ PKC $\epsilon$-translocating cells) (Fig. $2 B$ ).

Because cAMP activates PKA, we tested for the involvement of PKA in isoproterenol-induced PKC $\epsilon$ activation. Because the commonly used PKA inhibitor H89 also inhibits ligand binding to the $\beta_{2}$-AR (Penn et al., 1999), and inactive cAMP analogs such as Rp-cAMP also risk inhibiting other cAMP effectors, we used the PKA-specific membrane-permeable inhibitor CMIQ, which blocks the ATP-binding site of PKA (Lu et al., 1996). Preincubation (15 min) with CMIQ completely abrogated hyperalgesia in vivo induced by injection of the catalytic subunit of PKA (Slice and Taylor, 1989) (Fig. 2 B). Therefore, we preincubated the DRG cultures with CMIQ for 15 min with concentrations up to 1000fold greater than its $\mathrm{IC}_{50}$ value, before stimulation with isoproterenol. Intriguingly, in the presence of CMIQ, PKC $\epsilon$ still translocated to the plasma membrane, as in control conditions $(n=6)$ (Fig. 2A). Thus, although $\alpha_{\mathrm{s}}$ and AC are involved in the signal transduction from the $\beta_{2}$-AR to PKC $\epsilon$, PKA is not.

\section{Epac mediates PKC $\epsilon$ translocation}

Because cAMP is not signaling through PKA to induce PKC $\epsilon$ activity, we tested whether cAMP activation of Epac leads to translocation of PKC $\epsilon$ in dissociated DRG neurons. An Epacspecific activator, the cAMP analog CPTOMe, has been developed for the differentiation of PKA and Epac-mediated effects (Enserink et al., 2002; Rehmann et al., 2003). Stimulating neurons with this compound led to robust translocation of PKC $\epsilon$ to the plasma membrane, as seen with the activators of $\beta_{2}-\mathrm{AR}, \alpha_{\mathrm{s}}$, and $\mathrm{AC}$, corroborating the observation that the inhibition of PKA does not change the extent of PKC $\epsilon$ translocation (Fig. $2 B$ ) and, for the first time, placing Epac upstream of PKC.

Because CPTOMe induced a maximal number of cells with translocated PKC $\epsilon$ at $90 \mathrm{~s}(n=6 ; 20.3 \pm 2.6 \%$ vs $23.5 \pm 3.7 \%$ translocating neurons after CPTOMe stimulation for $30 \mathrm{~s}$ and $90 \mathrm{~s}$, respectively), this time point was used in the subsequent investigation of downstream events of CPTOMe stimulation of Epac.

\section{PKCe translocation is PLC and PLD dependent}

DAG, a product of members of the PLC family, can activate novel PKCs, such as PKC $\epsilon$. We tested for the involvement of phosphatidylcholate (PC) and phosphatidylinositol (PI) hydrolyzing PLCs, as well as for the involvement of phospholipase D in Epacinduced $\mathrm{PKC} \epsilon$ translocation.

To check for the involvement of PI-PLC, of which PLC $\epsilon$ is a member (Schmidt et al., 2001), we preincubated the cultures for 15 min with the PI-PLC inhibitor U73122 before stimulating with isoproterenol for $30 \mathrm{~s}$. The translocation of PKC $\epsilon$ was completely blocked by this inhibitor. In contrast, the inactive analog of U73122, U73343, produced only a slight reduction in translocation $(n=8 ; 0.3 \pm 0.3 \%$, and $15.3 \pm 1.9 \%$ PKC $\epsilon$-translocating cells in U73122- vs U73343-pretreated cultures; $19.0 \pm 3.0 \%$ PKC $\epsilon$-translocating cells in isoproterenol controls) (Fig. $3 A$ ).

The PI-PLC inhibitor U73122 and its negative control U73343 were solubilized in DMSO. By itself DMSO does not show any inhibitory influence over a wide range of concentrations, as exemplified here by the highest concentration used (dilution 1:200; $n=8$; $21.3 \pm 2.9 \%$ PKC $\epsilon$-translocating cells) (Fig. $3 A$ ).

In addition, DAG can be produced indirectly by PLD, which produces phosphatidic acid (PA) that is metabolized to DAG (Rizzo and Romero, 2002). Also, PLD-produced PA has been 
shown, in rat basophilic leukemia (RBL$2 \mathrm{H} 3$ ) cells, to act on PKC $\epsilon$ directly (Jose Lopez-Andreo et al., 2003). Therefore, cultures were pretreated with the competitive PLD inhibitor 1-butanol or its control, 2-butanol, for $15 \mathrm{~min}$ and then stimulated with $1 \mu \mathrm{M}$ isoproterenol for $30 \mathrm{~s}$. The use of 1-butanol, but not 2-butanol, results in a decrease in the number of PKC $\epsilon$ translocating cells, to baseline levels $(n=$ $8 ; 5.5 \pm 1.1 \%$ PKC $\epsilon$-translocating cells in 1-butanol-pretreated vs $16.0 \pm 2.4 \%$ in 2-butanol-pretreated cultures) (Fig. 3A).

The compound D-609 has been shown to block PC-hydrolyzing PLCs (PC-PLC) and leave the activity of PI-PLC and other PLCs unchanged (Schutze et al., 1992). Preincubation of DRG neuron cultures with D-609 for 15 min before stimulating with isoproterenol for $30 \mathrm{~s}$ produced no change in isoproterenol-induced translocation of PKC $\epsilon[n=8 ; 20.8 \pm 2.9 \%$ (D609 pretreated) PKC $\epsilon$-translocating cells in contrast to $19.0 \pm 3.0 \%$ in isoproterenol controls] (Fig. 3A), suggesting that PCPLCs are not involved in the activation of PKC $\epsilon$. Thus, both PI-PLC and PLD, but not PC-PLC, are necessary for the isoproterenol-induced translocation of PKC $\epsilon$.

To exclude that the activity of PLC and PLD leads to the activation of a PKC subtype different from $\mathrm{PKC} \epsilon$, which then in turn contributes to the activation of PKC $\epsilon$, we used the PKC inhibitor BIM, which inhibits PKC activity by blocking the ATP-binding site, but which does not inhibit translocation of PKCs in the course of activation (Toullec et al., 1991). Again, the cultures were pretreated for $15 \mathrm{~min}$ with the inhibitor before stimulation with isoproterenol. There was no reduction in cells, showing PKC $\epsilon$ translocation $(n=8$; PKC $\epsilon$ translocation in $19.8 \pm$ $1.3 \%$ in BIM-treated vs $19.0 \pm 3.0 \%$ in untreated isoproterenol-stimulated cells) (Fig. $3 A)$. Therefore, PI-PLC and PLD are acting not via a different PKC subtype but on PKC $\epsilon$ directly.

\section{PLC and PLD are downstream of Epac} To investigate whether PI-PLC and PLD are downstream of the $\alpha_{s} / \mathrm{AC} / \mathrm{cAMP} / \mathrm{Epac}$ signaling pathway delineated with the previous experiments and not downstream of a possible parallel-signaling cascade [e.g., transactivation of a receptor tyrosine kinase leading to lipase activation (Luttrell et al., 1997; Lee and Chao, 2001], we evaluated for the influence of U73122 and U73343 or 1-butanol and 2-butanol on PKC $\epsilon$ translocation after direct activation of Epac with CPTOMe. Again, cultures were pretreated with the respective inhibitor or its inactive control compound for $15 \mathrm{~min}$ before adding the Epac activator CPTOMe and stimulating for $90 \mathrm{~s}$. As shown in Figure $3 B$, the activity of both phospholipases is also necessary for the translocation of PKC $\epsilon$ to occur in response to direct activation of $\operatorname{Epac}(n=6$;
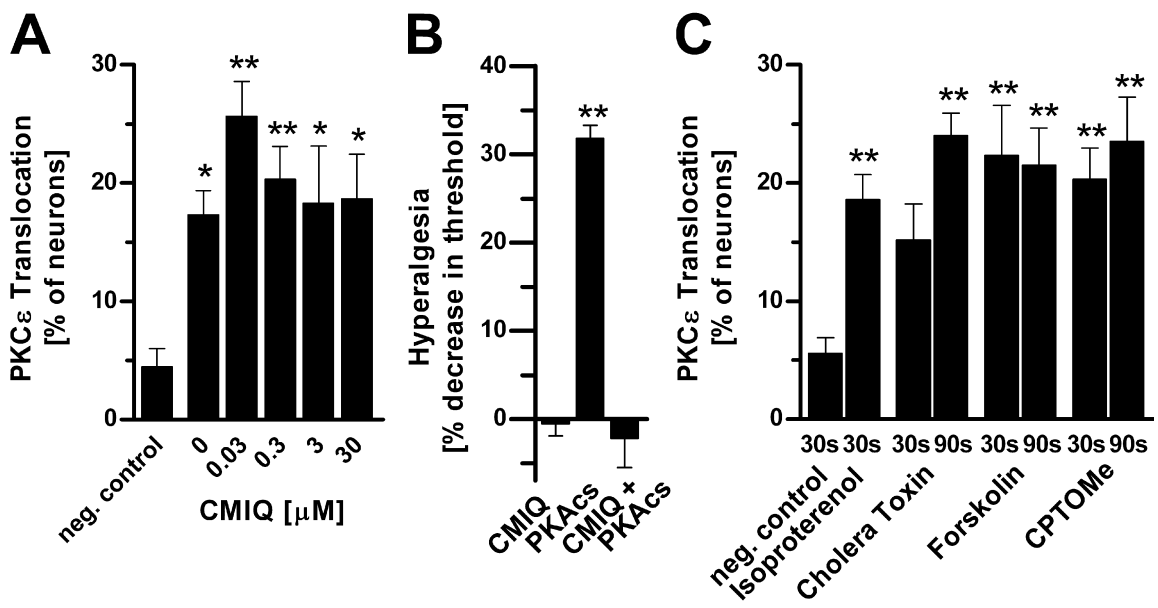

Figure 2. G-protein $\alpha_{s}$, adenylyl cyclase, and Epac, but not PKA, are involved in PKC $\epsilon$ translocation. $\boldsymbol{A}$, DRG cultures were pretreated for $15 \mathrm{~min}$ with indicated concentrations [1, 10, 100, and $1000 \times$ the $\left.\mathrm{CMIQ}_{-\mathrm{IC}}(0.03-30 \mu \mathrm{M})\right]$ of the PKA-specific inhibitor CMIQ (Lu et al., 1996) before stimulation with $1 \mu \mathrm{m}$ isoproterenol for $30 \mathrm{~s}$. Cultures not treated with either CMIQ or isoproterenol served as negative controls. $\boldsymbol{B}$, Injection of the PKA inhibitor CMIQ $(2.5 \mu \mathrm{g} / 2.5 \mu \mathrm{l})$ intradermally in rat paws did not change the mechanical paw-withdrawal threshold. Injection of active PKA [PKA catalytic subunit (PKAcs); $25 \mathrm{U} / 2.5 \mu \mathrm{ll}$ induced robust mechanical hyperalgesia. Preinjection of CMIQ 15 min before the injection of PKAcs completely blocked the PKA-induced hyperalgesia in vivo. $\mathbf{C}$, Cultures were stimulated with activators of G-protein $\alpha_{\mathrm{s}}$ (cholera toxin; $1 \mu \mathrm{g} / \mathrm{ml}$ ), adenylyl cyclase (forskolin, $5 \mu \mathrm{M}$ ), and Epac (СРTOMe, $10 \mu \mathrm{M})$, for the indicated time. Unstimulated cells served as a negative control, and isoproterenol (1 $\mu \mathrm{M}, 30 \mathrm{~s})$-treated cells served as a positive control. ${ }^{*} p<0.05 ;{ }^{* *} p<0.01$. Error bars represent SEM.
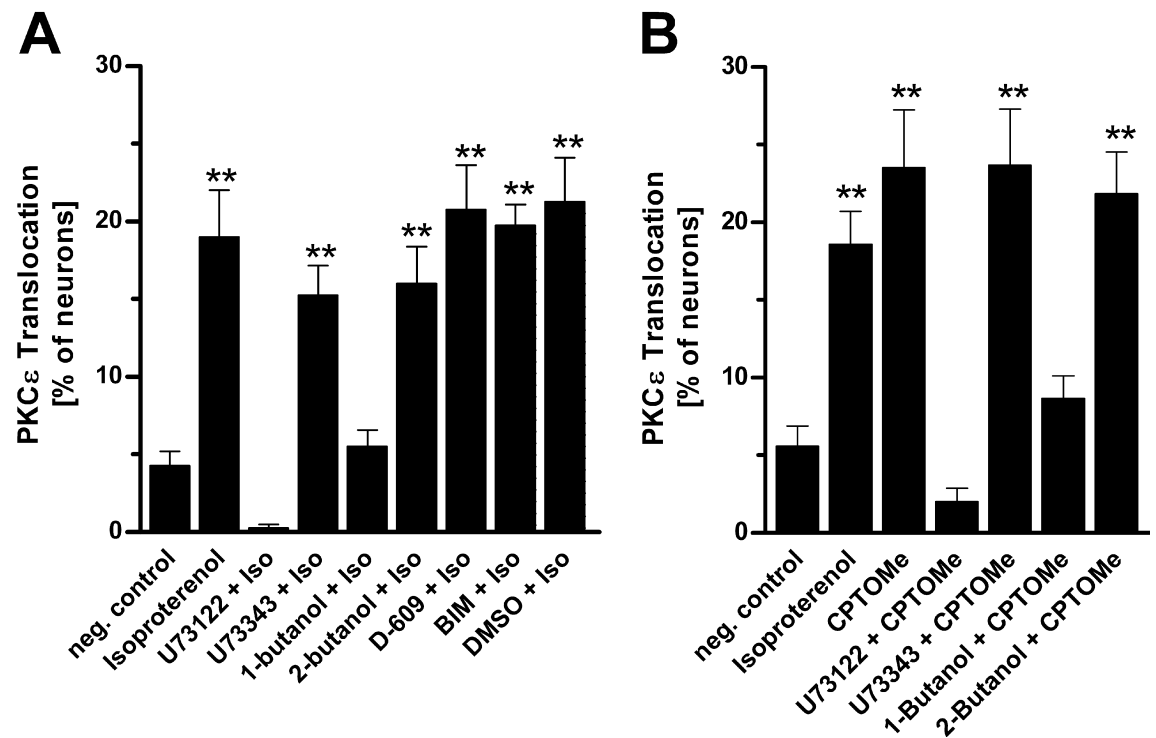

Figure 3. $\quad \beta_{2}$-AR-induced Epac-mediated translocation of PKC $\epsilon$ requires the activity of both PI-PLC and PLD. A, Percentage of neurons demonstrating PKC $\epsilon$ translocation to the plasma membrane after stimulation with isoproterenol (Iso; $1 \mu \mathrm{M}, 30 \mathrm{~s})$. Cultures were pretreated for 15 min with the indicated inhibitors: PC-PLC inhibitor (D-609; $30 \mu \mathrm{M})$, PI-PLC inhibitor (U73122; 10 $\mu \mathrm{M})$, inactive homolog of U73122 (U73343; $10 \mu \mathrm{M})$, PLD inhibitor (1-butanol; $50 \mathrm{mM}$ ), inactive homolog for 1-butanol (2-butanol; $50 \mathrm{~mm}$ ); PKC kinase inhibitor (BIM; $100 \mathrm{~nm}$ ). Concentrations used are $\sim 10$ times the reported $\mathrm{I}_{50}$ values. $\boldsymbol{B}$, Percentage of neurons demonstrating PKC $\epsilon$ translocation to the plasma membrane after stimulation with the Epac-specific activator CPTOMe (10 $\mu \mathrm{M}$, 90 s). Inhibitors were used as in $\boldsymbol{A}$. ${ }^{* *} p<0.01$. Error bars represent SEM.

PKC $\epsilon$ translocation in $2.0 \pm 0.9 \%$ of U73122, $23.7 \pm 3.6 \%$ of U73343, $8.7 \pm 1.5 \%$ of 1-butanol, $21.8 \pm 2.7 \%$ of 2-butanol-pretreated and CPTOMe-stimulated cells, and $23.5 \pm 3.7 \%$ in CPTOMe stimulated cells) (Fig. 3B).

\section{$\boldsymbol{\beta}_{2}$-Adrenergic receptor-induced translocation of PKC $\epsilon$} occurs in IB4 $(+)$ neurons

Although almost all neurons expressed both PKC $\epsilon$ and $\beta_{2}$-AR $[94.9 \% \pm 1.8 \%(n=409)$ and $99.8 \% \pm 0.2 \%(n=407)$ of 

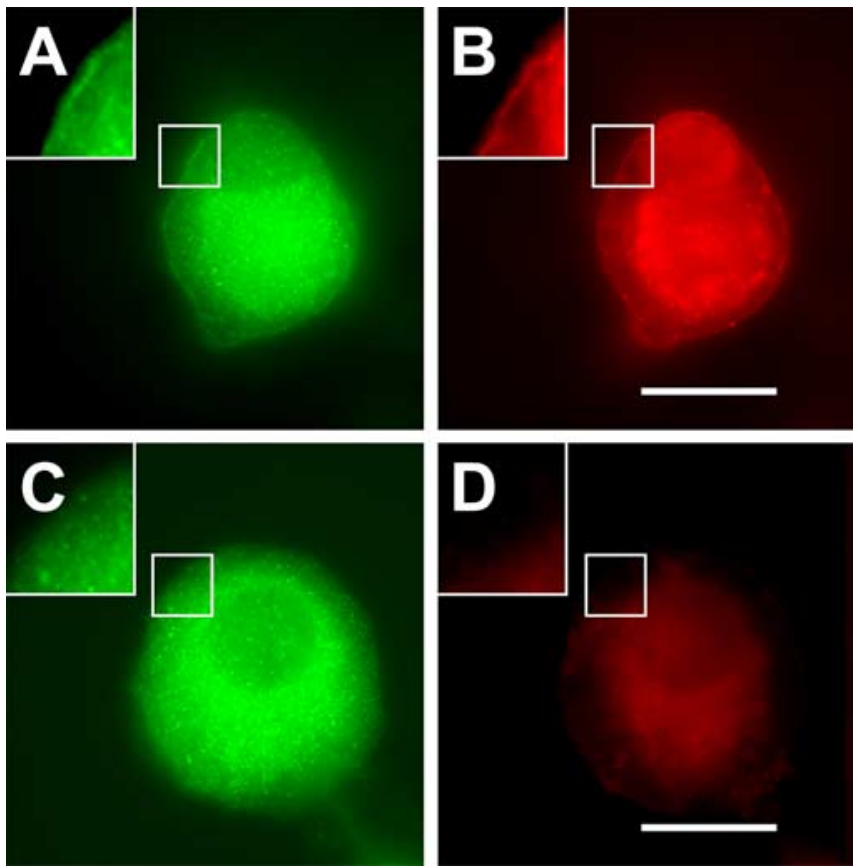

Figure 4. $A-D, P K C \epsilon$ translocation and IB4 double-staining epifluorescence images of double-stained cells tested for PKC $\epsilon$ ( $\boldsymbol{A}$ and $\boldsymbol{C} ; 1: 1000$ diluted) and IB4 ( $\boldsymbol{B}$ and $\boldsymbol{D} ; 1: 100$ diluted). $A, C$, Although the cell in the top row is translocating PKC $\epsilon$ to the plasma membrane $(\boldsymbol{A})$, it also shows clear plasma membrane staining of the IB4 epitope ( $(\boldsymbol{C})$. In contrast, the cell in $\boldsymbol{C}$ does not translocate PKC $\epsilon$ and is not positive for the IB4 epitope (D). Insets, Enlarged area indicated by the white frame. Scale bar, $20 \mu \mathrm{m}$.

neurons, respectively], translocation of PKC $\epsilon$ was detected in only $20-35 \%$ of neurons. Because the culture system used comprises a mixture of sensory neurons subserving different function, we sought to identify a subpopulation of neurons in which translocation occurs using double staining with the marker for nonpeptidergic nociceptive neurons, IB4. The vast majority of neurons translocating PKC $\epsilon$ after $\beta_{2}$-AR stimulation showed strong IB4 plasma-membrane fluorescence signal (Fig. 4) (88.6 \pm $2.4 \%$ of PKC $\epsilon$-translocating cells show IB4 staining (evaluated cultures, $n=4$; percentage of IB4 positive per PKC $\epsilon$ translocating cells, 88.9, 92.9, 81.8, and 90.9\%; total number of PKC $\epsilon$-translocating cells, 45).

\section{Epac activates PKC $\epsilon$ to induce hyperalgesia}

To determine whether the signaling pathway upstream of PKC $\epsilon$ in cultured nociceptive neurons also applied to $\mathrm{PKC} \epsilon$ signaling in nociceptor sensitization/hyperalgesia in vivo, behavioral experiments were performed. The same model as that used to establish the role of $\mathrm{PKC} \epsilon$ in $\beta$-AR agonist-induced hyperalgesia was applied (Khasar et al., 1999b). We found that, in vivo, direct activation of Epac with CPTOMe robustly induces mechanical hyperalgesia [reduction of paw-withdrawal threshold by $37.7 \pm 1.9 \%$ after epinephrine $(n=6), 34.6 \pm 1.6 \%$ after CPTOMe $(n=12)$, and increase of threshold by $0.4 \pm 1.8$ after saline injection $(n=$ 6)] (Fig. 5A).

Subsequently, we tested whether Epac mediates hyperalgesia through the activation of PKC $\epsilon$. We therefore stimulated the onset of hyperalgesia with CPTOMe after the injection of the specific PKC $\epsilon$ inhibitor $\epsilon \mathrm{V} 1-2$. As shown in Figure $5 A, \epsilon \mathrm{V} 1-2$ inhibited hyperalgesia induced by CPTOMe [reduction of pawwithdrawal threshold by $34.6 \pm 1.6 \%$ after CPTOMe $(n=12)$, increase by $1.6 \pm 2.7 \%$ after $\epsilon \mathrm{V} 1-2(n=6)$, and increase by $3.9 \pm$
$2.1 \%$ after CPTOMe into $\epsilon \mathrm{V} 1-2$-pretreated paws $(n=6)]$. Therefore, the in vivo activation of Epac also leads to the activation of PKC $\epsilon$, which in turn leads to mechanical hyperalgesia.

Finally, to establish the role of PI-PLC and PLD as mediators of $\beta_{2}$-AR agonist and Epac-induced hyperalgesia, we preinjected the paws with the respective inhibitors and their inactive controls, U73122/U73343 (PI-PLC) and 1-butanol/2-butanol (PLD), before the stimulation with either epinephrine or CPTOMe. Without stimulation, neither inhibitor influenced the baseline sensitivity of the rats $(n=6$; U73122, 4.4\% $\pm 1.3 \%$; U73343, $2.8 \% \pm 1.9 \%$; 1-butanol, $-0.0 \% \pm 1.8 \%$; 2-butanol, $-8 \% \pm 1.7 \%$ ) (Fig. $5 B$ ). However, as seen in vitro, U73122 as well as 1-butanol inhibited the onset of CPTOMe-induced hyperalgesia [CPTOMe, $31.7 \% \pm 0.8 \%(n=12)$; U73122/CPTOMe, $-2.5 \% \pm 2.0 \%(n=6)$; 1-butanol/CPTOMe, $-0.5 \% \pm 1.8 \%$ $(n=6)]$, whereas the respective negative controls, U73343 and 2-butanol, did not [U73343/CPTOMe, 30.9\% $\pm 1.9 \%(n=6)$; 2-butanol/CPTOMe, $33.4 \% \pm 1.7 \%(n=6)]$. Thus, in vivo, both PI-PLC and PLD could be established as essential mediators of mechanical hyperalgesia.

\section{Discussion}

Epac mediates cross talk $\mathrm{G} \boldsymbol{\alpha}_{\mathrm{s}} / \mathrm{cAMP}$ to PKC€

Extensive research on G-protein-coupled receptor (GPCR) signaling has identified different pathways leading to the activation of PKC. The G-proteins $\alpha_{\mathrm{q}}$ and $\beta \gamma$ (Gudermann et al., 1997) or transactivation of growth factor receptors (Luttrell et al., 1997; Lee and Chao, 2001), but not the G-protein $\alpha_{\mathrm{s}}$, have been shown to lead to the activation of phospholipases and thereby the activation of PKCs. Recently, studies of nociceptor sensitization, in which AC was activated with forskolin, suggested that the G-protein $\alpha_{s}$ might activate PKC (Gold et al., 1998; Parada et al., 2005). Using the well established activator of $\alpha_{\mathrm{s}}$, cholera toxin, of $\mathrm{AC}$, forskolin, and the CAMP analog, CPTOMe, we provide proof of principle that, indeed, the G-protein $\alpha_{\mathrm{s}}$ also mediates GPCR signaling toward activation of PKC $\epsilon$.

A mechanism connecting the CAMP and PKC signaling pathways has not been elucidated. We found that the PKA inhibitor CMIQ, which blocks the ATP-binding site of PKA (Lu et al., 1996), did not abolish $\beta_{2}$-AR-induced translocation of PKC $\epsilon$ in DRG neurons, indicating that the $\alpha_{\mathrm{s}}$ /cAMP second-messenger signaling pathway branches upstream of PKA before activating PKC $\epsilon$. We tested the hypothesis that the recently identified downstream mediator of cAMP, Epac (de Rooij et al., 1998; Kawasaki et al., 1998), could mediate this cross talk. Although Epac is known to activate MAPKs, it is not known to activate PKCs. Using the Epac-specific cAMP analog CPTOMe, we show that the activation of Epac induces PKC $\epsilon$ translocation and therefore mediates the cAMP/PKC cross talk in DRG neurons.

\section{Epac activates PKC $\epsilon$ via PI-PLC and PLD}

DAG generated by phospholipases can activate novel PKCs, such as PKC $\epsilon$. The $\beta_{2}$-AR has been shown in HEK293 (human embryonic kidney 293) cells to lead to activation of PLC $\epsilon$ (Schmidt et al., 2001), a PLC isoform for which there are no specific activators or inhibitors. Nevertheless, using the inhibitor U73122, we were able to narrow down the phospholipase involved in PKC $\epsilon$ activation to be of the same class as PLC $\epsilon$, namely a PI-PLC, and to demonstrate its essential role in $\beta_{2}$-AR/Epac-induced activation of PKC $\epsilon$.

Although PLCs often provide the first surge in DAG production, PLD can also contribute to a rise in DAG by production of PA, which then can be converted into DAG (Nishizuka, 1992; 
Clapham and Neer, 1993). Surprisingly, however, we found that not only is PLD involved, but it is necessary for the translocation of PKC $\epsilon$. Of note in this regard, DAG as well as PA have been shown recently in RBL-2H3 cells to bind PKC $\epsilon$ at two different sites and to contribute to both the attachment and activation of PKC $\epsilon$ to the plasma membrane (Jose Lopez-Andreo et al., 2003). We now show that PLD is an essential component of $\mathrm{PKC} \epsilon$ translocation in nociceptors.

\section{Epac mediates PKC $\epsilon$-dependent} mechanical hyperalgesia

We investigated whether activation of Epac also leads, through PI-PLC and PLD in vivo, to $\mathrm{PKC} \epsilon$-dependent mechanical hyperalgesia. PKC $\epsilon$-dependent hyperalgesia has been shown to require the activity of PKC $\epsilon$ in nociceptive neurons, leading to modulation of the tetrodotoxinresistant (TTX-R) sodium channel, which is one effector component in peripheral pain (Khasar et al., 1999b; Parada et al., 2003b). Injection of modulators of PKC $\epsilon$ into the hindpaw of rats has been proven to be a suitable way to modulate the activity of PKC $\epsilon$ in nociceptive neurons and thereby to modulate PKC $\epsilon$-dependent hyperalgesia (Khasar et al., 1999b; Parada et al., 2003b). We found that injections of the Epac activator CPTOMe induces mechanical hyperalgesia to an extent similar to the $\beta_{2}$-AR acting epinephrine. Epac activation also leads in vivo to activation of $\mathrm{PKC} \epsilon$, because the use of the PKC $\epsilon$-specific inhibitor, $\epsilon \mathrm{V} 1-2$, completely attenuated Epac activator-induced mechanical hyperalgesia, confirming the in vitro delineated signaling pathway.

The central role of both phospholipases, PI-PLC and PLD, in Epac/PKC $\epsilon$-induced hyperalgesia was confirmed in vivo. Inhibition of either PI-PLC with U73122 or inhibition of PLD with the inhibitor 1-butanol completely abolished Epacmediated mechanical hyperalgesia, whereas the respective inhibitor controls, U73343 and 2-butanol, showed no effect. PI-PLC and PLD activity have been thereby introduced as new and essential components to $\beta_{2}$-AR-induced/PKC $\epsilon$-mediated mechanical hyperalgesia.

\section{Epac activates PKC $\epsilon$ in IB4(+) nociceptors}

The IB4 epitope is found on GDNF (glial cell line-derived neurotrophic factor)-dependent, small-diameter nociceptive neurons and marks $\sim 30 \%$ of DRG neurons (Molliver and Snider, 1997; Hunt and Mantyh, 2001). These neurons make up 70\% of neurons innervating the epidermis (Lu et al., 2001), project to lamina IIi of the spinal cord, and are suggested to be involved in neuropathic pain (Molliver et al., 1997; Bennett et al., 1998; Boucher et al., 2000). Although IB4 has been used extensively for descriptive investigations of changes in protein expression in models of pain, little is known about the functional and mechanistic importance of these neurons. We observed translocation of PKC $\epsilon$ in only $\sim 20-35 \%$ of cultured DRG neurons. Although we found that $\beta_{2}$-AR, Epac (data not shown), and PKC $\epsilon$ are expressed in nearly all DRG neurons, translocation of PKC $\epsilon$ was highly correlated with the expression of the IB4 epitope. The molecular basis for this specificity remains elusive and could be based on differential expression of additional signaling components not identified thus far or on differential regulation of signaling components. Our observation corroborates IB4 $(+)$ neurons as nociceptors and suggests a functional difference between IB4-positive and IB4-negative/peptidergic nociceptors. Because the TTX-R sodium current is modulated by PKC $\epsilon$ as well as other mechanisms (Khasar et al., 1999b), it will be interesting to also investigate whether these additional mechanisms are present in IB4(+) neurons. Although other molecules involved in nociception, such as TRPV1 (transient receptor potential vanilloid receptor-1), are expressed overlapping with different subpopulations of DRG neurons (Guo et al., 1999; Zwick et al., 2002), we describe with this observation the first cellular mechanism restricted to the IB4 $(+)$ subtype of nociceptive neurons.

\section{Epac and other signaling pathways mediating hyperalgesia} In conclusion, by delineating a signaling pathway leading to the activation of PKC $\epsilon$ in vitro and in vivo (for overview, see supplemental data, available at www.jneurosci.org as supplemental material), we present a detailed analysis of an intracellular signaling pathway in sensory neurons underlying pain. We thereby elucidate a novel mechanism of signal transduction, a cross talk between the two ubiquitous signaling pathways cAMP and PKC, which are both used in a wide variety of mechanisms, such as neuronal plasticity. We provide evidence that Epac is a key element in this cross talk. Importantly, this signaling pathway in DRG neurons is restricted to the IB4 $(+)$ nociceptors, establishing a first mechanism specific to this subpopulation of nociceptors. Delineating the cascade leading to activation of PKC $\epsilon$, we introduce two new potential targets for treatment of pain, Epac and PLD. In addition, we provide proof of principle that not only the G-proteins $\alpha_{\mathrm{q}}$ and $\beta \gamma$ but also $\alpha_{\mathrm{s}}$ can activate PKC.

Our results provide a powerful entry point to also start investigating the intracellular signaling pathways in hyperalgesia in- 
duced by other inflammatory mediators. Intriguingly, the literature on Epac and its downstream target, Rap1, also suggests even further cross talk to other pathways important in nociceptor function, such as PKA and MAPK (Khasar et al., 1999b; Aley et al., 2001; Stork and Schmitt, 2002), integrins (Bos et al., 2003; Rangarajan et al., 2003; Dina et al., 2004), and growth factor receptors (Boucher et al., 2000).

\section{References}

Aley KO, Messing RO, Mochly-Rosen D, Levine JD (2000) Chronic hypersensitivity for inflammatory nociceptor sensitization mediated by the epsilon isozyme of protein kinase C. J Neurosci 20:4680-4685.

Aley KO, Martin A, McMahon T, Mok J, Levine JD, Messing RO (2001) Nociceptor sensitization by extracellular signal-regulated kinases. J Neurosci 21:6933-6939.

Bennett DL, Michael GJ, Ramachandran N, Munson JB, Averill S, Yan Q, McMahon SB, Priestley JV (1998) A distinct subgroup of small DRG cells express GDNF receptor components and GDNF is protective for these neurons after nerve injury. J Neurosci 18:3059-3072.

Bond RA, Leff P, Johnson TD, Milano CA, Rockman HA, McMinn TR, Apparsundaram S, Hyek MF, Kenakin TP, Allen LF, Lefkowitz RJ (1995) Physiological effects of inverse agonists in transgenic mice with myocardial overexpression of the beta 2-adrenoceptor. Nature 374:272-276.

Bos JL, de Bruyn K, Enserink J, Kuiperij B, Rangarajan S, Rehmann H, Riedl J, de Rooij J, van Mansfeld F, Zwartkruis F (2003) The role of Rap1 in integrin-mediated cell adhesion. Biochem Soc Trans 31:83-86.

Boucher TJ, Okuse K, Bennett DL, Munson JB, Wood JN, McMahon SB (2000) Potent analgesic effects of GDNF in neuropathic pain states. Science 290:124-127.

Cesare P, Dekker LV, Sardini A, Parker PJ, McNaughton PA (1999) Specific involvement of PKC-epsilon in sensitization of the neuronal response to painful heat. Neuron 23:617-624.

Clapham DE, Neer EJ (1993) New roles for G-protein beta gamma-dimers in transmembrane signalling. Nature 365:403-406.

de Rooij J, Zwartkruis FJ, Verheijen MH, Cool RH, Nijman SM, Wittinghofer A, Bos JL (1998) Epac is a Rap1 guanine-nucleotide-exchange factor directly activated by cyclic AMP. Nature 396:474-477.

Dina OA, Barletta J, Chen X, Mutero A, Martin A, Messing RO, Levine JD (2000) Key role for the $\epsilon$ isoform of protein kinase $\mathrm{C}$ in painful alcoholic neuropathy in the rat. J Neurosci 20:8614-8619.

Dina OA, Chen X, Reichling D, Levine JD (2001) Role of protein kinase Cepsilon and protein kinase A in a model of paclitaxel-induced painful peripheral neuropathy in the rat. Neuroscience 108:507-515.

Dina OA, McCarter GC, de Coupade C, Levine JD (2003) Role of the sensory neuron cytoskeleton in second messenger signaling for inflammatory pain. Neuron 39:613-624.

Dina OA, Parada CA, Yeh J, Chen X, McCarter GC, Levine JD (2004) Integrin signaling in inflammatory and neuropathic pain in the rat. Eur J Neurosci 19:634-642.

Dorn II GW, Mochly-Rosen D (2002) Intracellular transport mechanisms of signal transducers. Annu Rev Physiol 64:407-429.

Enserink JM, Christensen AE, de Rooij J, van Triest M, Schwede F, Genieser HG, Doskeland SO, Blank JL, Bos JL (2002) A novel Epac-specific cAMP analogue demonstrates independent regulation of Rapl and ERK. Nat Cell Biol 4:901-906.

Gold MS, Levine JD, Correa AM (1998) Modulation of TTX-R INa by PKC and PKA and their role in PGE2-induced sensitization of rat sensory neurons in vitro. J Neurosci 18:10345-10355.

Gudermann T, Schoneberg T, Schultz G (1997) Functional and structural complexity of signal transduction via G-protein-coupled receptors. Annu Rev Neurosci 20:399-427.

Guo A, Vulchanova L, Wang J, Li X, Elde R (1999) Immunocytochemical localization of the vanilloid receptor 1 (VR1): relationship to neuropeptides, the P2X3 purinoceptor and IB4 binding sites. Eur J Neurosci 11:946-958.

Hunt SP, Mantyh PW (2001) The molecular dynamics of pain control. Nat Rev Neurosci 2:83-91.

Johnson JA, Gray MO, Chen CH, Mochly-Rosen D (1996) A protein kinase C translocation inhibitor as an isozyme-selective antagonist of cardiac function. J Biol Chem 271:24962-24966.

Jose Lopez-Andreo M, Gomez-Fernandez JC, Corbalan-Garcia S (2003)
The simultaneous production of phosphatidic acid and diacylglycerol is essential for the translocation of protein kinase Cepsilon to the plasma membrane in RBL-2H3 cells. Mol Biol Cell 14:4885-4895.

Joseph EK, Levine JD (2003a) Sexual dimorphism in the contribution of protein kinase $\mathrm{C}$ isoforms to nociception in the streptozotocin diabetic rat. Neuroscience 120:907-913.

Joseph EK, Levine JD (2003b) Sexual dimorphism for protein kinase c epsilon signaling in a rat model of vincristine-induced painful peripheral neuropathy. Neuroscience 119:831-838.

Kawasaki H, Springett GM, Mochizuki N, Toki S, Nakaya M, Matsuda M, Housman DE, Graybiel AM (1998) A family of cAMP-binding proteins that directly activate Rap 1 . Science 282:2275-2279.

Keiper M, Stope MB, Szatkowski D, Bohm A, Tysack K, Vom Dorp F, Saur O, Oude Weernink PA, Evellin S, Jakobs KH, Schmidt M (2004) Epac- and $\mathrm{Ca}^{2+}$-controlled activation of Ras and extracellular signal-regulated kinases by Gs-coupled receptors. Involvement of Rap2B-activated phospholipase C-epsilon. J Biol Chem 279:46497-46508.

Khasar SG, Ouseph AK, Chou B, Ho T, Green PG, Levine JD (1995) Is there more than one prostaglandin E receptor subtype mediating hyperalgesia in the rat hindpaw? Neuroscience 64:1161-1165.

Khasar SG, McCarter G, Levine JD (1999a) Epinephrine produces a betaadrenergic receptor-mediated mechanical hyperalgesia and in vitro sensitization of rat nociceptors. J Neurophysiol 81:1104-1112.

Khasar SG, Lin YH, Martin A, Dadgar J, McMahon T, Wang D, Hundle B, Aley KO, Isenberg W, McCarter G, Green PG, Hodge CW, Levine JD, Messing RO (1999b) A novel nociceptor signaling pathway revealed in protein kinase C epsilon mutant mice. Neuron 24:253-260.

Lee FS, Chao MV (2001) Activation of Trk neurotrophin receptors in the absence of neurotrophins. Proc Natl Acad Sci USA 98:3555-3560.

Lu J, Zhou XF, Rush RA (2001) Small primary sensory neurons innervating epidermis and viscera display differential phenotype in the adult rat. Neurosci Res 41:355-363.

Lu ZX, Quazi NH, Deady LW, Polya GM (1996) Selective inhibition of cyclic AMP-dependent protein kinase by isoquinoline derivatives. Biol Chem Hoppe Seyler 377:373-384.

Luttrell LM, Della Rocca GJ, van Biesen T, Luttrell DK, Lefkowitz RJ (1997) Gbetagamma subunits mediate Src-dependent phosphorylation of the epidermal growth factor receptor. A scaffold for $G$ protein-coupled receptor-mediated Ras activation. J Biol Chem 272:4637-4644.

Molliver DC, Snider WD (1997) Nerve growth factor receptor TrkA is down-regulated during postnatal development by a subset of dorsal root ganglion neurons. J Comp Neurol 381:428-438.

Molliver DC, Wright DE, Leitner ML, Parsadanian AS, Doster K, Wen D, Yan Q, Snider WD (1997) IB4-binding DRG neurons switch from NGF to GDNF dependence in early postnatal life. Neuron 19:849-861.

Neves SR, Ram PT, Iyenagar R (2002) G protein pathways. Science 296:1636-1639.

Nishizuka Y (1992) Intracellular signaling by hydrolysis of phospholipids and activation of protein kinase C. Science 258:607-614.

Numazaki M, Tominaga T, Toyooka H, Tominaga M (2002) Direct phosphorylation of capsaicin receptor VR1 by protein kinase Cepsilon and identification of two target serine residues. J Biol Chem 277:13375-13378.

Parada CA, Yeh JJ, Joseph EK, Levine JD (2003a) Tumor necrosis factor receptor type-1 in sensory neurons contributes to induction of chronic enhancement of inflammatory hyperalgesia in rat. Eur J Neurosci 17:1847-1852.

Parada CA, Yeh JJ, Reichling DB, Levine JD (2003b) Transient attenuation of protein kinase Cepsilon can terminate a chronic hyperalgesic state in the rat. Neuroscience 120:219-226.

Parada CA, Reichling DB, Levine JD (2005) Chronic hyperalgesic priming in the rat involves a novel interaction between cAMP and PKCvarepsilon second messenger pathways. Pain 113:185-190.

Parekh DB, Ziegler W, Parker PJ (2000) Multiple pathways control protein kinase C phosphorylation. EMBO J 19:496-503.

Penn RB, Parent JL, Pronin AN, Panettieri Jr RA, Benovic JL (1999) Pharmacological inhibition of protein kinases in intact cells: antagonism of beta adrenergic receptor ligand binding by H-89 reveals limitations of usefulness. J Pharmacol Exp Ther 288:428-437.

Rangarajan S, Enserink JM, Kuiperij HB, de Rooij J, Price LS, Schwede F, Bos JL (2003) Cyclic AMP induces integrin-mediated cell adhesion through Epac and Rap1 upon stimulation of the beta 2-adrenergic receptor. J Cell Biol 160:487-493. 
Rehmann H, Schwede F, Doskeland SO, Wittinghofer A, Bos JL (2003) Ligand-mediated activation of the cAMP-responsive guanine nucleotide exchange factor Epac. J Biol Chem 278:38548-38556.

Rizzo M, Romero G (2002) Pharmacological importance of phospholipase $\mathrm{D}$ and phosphatidic acid in the regulation of the mitogen-activated protein kinase cascade. Pharmacol Ther 94:35-50.

Schmidt M, Evellin S, Weernink PA, von Dorp F, Rehmann H, Lomasney JW, Jakobs KH (2001) A new phospholipase-C-calcium signalling pathway mediated by cyclic AMP and a Rap GTPase. Nat Cell Biol 3:1020-1024.

Schutze S, Potthoff K, Machleidt T, Berkovic D, Wiegmann K, Kronke M (1992) TNF activates NF-kappa B by phosphatidylcholine-specific phospholipase C-induced "acidic" sphingomyelin breakdown. Cell 71:765-776.

Slice LW, Taylor SS (1989) Expression of the catalytic subunit of cAMPdependent protein kinase in Escherichia coli. J Biol Chem 264:20940-20946.
Stork PJ, Schmitt JM (2002) Crosstalk between cAMP and MAP kinase signaling in the regulation of cell proliferation. Trends Cell Biol 12:258-266.

Sweitzer SM, Wong SM, Peters MC, Mochly-Rosen D, Yeomans DC, Kendig JJ (2004) Protein kinase C epsilon and gamma: involvement in formalin-induced nociception in neonatal rats. J Pharmacol Exp Ther 309:616-625.

Taiwo YO, Levine JD (1989) Contribution of guanine nucleotide regulatory proteins to prostaglandin hyperalgesia in the rat. Brain Res 492:400-403.

Toullec D, Pianetti P, Coste H, Bellevergue P, Grand-Perret T, Ajakane M, Baudet V, Boissin P, Boursier E, Loriolle F, Duhamel L, Charon D, Kirilovsky J (1991) The bisindolylmaleimide GF 109203X is a potent and selective inhibitor of protein kinase C. J Biol Chem 266:15771-15781.

Zwick M, Davis BM, Woodbury CJ, Burkett JN, Koerber HR, Simpson JF, Albers KM (2002) Glial cell line-derived neurotrophic factor is a survival factor for isolectin $\mathrm{B} 4$-positive, but not vanilloid receptor 1-positive, neurons in the mouse. J Neurosci 22:4057-4065. 